\title{
Dissociative Disorder
}

National Cancer Institute

\section{Source}

National Cancer Institute. Dissociative Disorder. NCI Thesaurus. Code C92197.

A category of psychiatric disorders which are characterized by a disruption in the usually integrated functions of consciousness, memory, identity, and/or perception of the environment. 